\title{
Effects of formation and penetration properties of biodegradable montmorillonite/chitosan nanocomposite film on the barrier of package paper
}

\author{
Shanhui Wang ${ }^{\text {a }}$, Yi Jing ${ }^{\text {a, * }}$ \\ ${ }^{a}$ Department of Light Industry Science and Engineering, Nanjing Forestry University, Nanjing 210037, PR China
}

Keywords:

Chitosan

Montmorillonite/chitosan

nanocomposite

Film formation

Penetration properties

Barrier properties

\section{A B S T RA C T}

The conventional package paper was coated with biodegradable montmorillonite/chitosan nanocomposite, in order to extend the application scope of paper. The effect of coating weight, montmorillonite dispersion rate, montmorillonite and dispersant content on the surface and penetration properties of montmorillonite/chitosan nanocomposite coated paper were being investigated. The surface properties of the coated paper were observed by using Scanning electron microscope (SEM) and Atomic force microscope (AFM). The water permeation and water vapor barrier properties were confirmed through penetration dynamics analyzer (PDA) and water vapor permeability tester (WVP), respectively. The results indicated that montmorillonite/chitosan nanocomposite had a poorer formation than pure chitosan, but it had better water vapor barrier properties. The paper coated with lower content of montmorillonite, or with higher dispersion speed and dispersant content, had better smoothness and elongation. Additionally, the coated paper had excellent barrier properties under the conditions of high montmorillonite and dispersant content, dispersion rate and coating weight.

\section{Introduction}

Due to environmental pollution and resources shortage had limited the development of packaging materials, people began to turn attention to bio-based materials. Bio-based packaging materials are made from cellulose, starch, protein, chitosan and their bio-derivative, which chitosan is widely favored because of its good film,

$\square$ Corresponding author at: Nanjing Forestry University, Nanjing,

210037, PR China.

E-mail addresses: jingyi@njfu.com.cn (Yi Jing), shanhui929@163.com (Shanhui Wang).

biocompatible, biodegradable and antibacterial properties (Kampeerapappun et al., 2007; Dias et al., 2014; He et al., 2014).

Biodegradable paper was a kind of conventional packaging material and applied widely in the packaging sector. Paper consisted mainly of natural plant fibers. Fibers connected each other by hydrogen bonding. Because the main compositions of fibers were hydrophilic cellulose and hemicellulose, paper was hydrophilic and porous. So paper has weaker the barrier 
properties against oxygen and water vapor penetration, compared with plastics material. Pure chitosan had a disadvantage for the application in the high-humid condition because of its hydrophilic nature and its poor mechanical properties. Moreover, its thermal stability, hardness, and gas barrier property were not adequate enough to meet the wide ranges of potential applications (Reis et al., 2011; Lertsutthiwong et al., 2012; Lewandowska et al., 2014). But the barrier of paper against water vapor and oxygen could be improved by coating montmorillonite/chitosan nanocomposite $(\mathrm{Mt} / \mathrm{Cs})$ on the surface of paper (Xu et al., 2005).

The addition of layered silicates and in particular montmorillonite (Mt) in chitosan has been extensively studied in some fields. (Han et al., 2010; Kittinaovarat et al., 2010; Hsu et al., 2012; Azhar et al., 2014; Giannakas et al., 2014). Mt, a clay mineral, is the most widely used silicate in polymer nanocomposites (Lin et al., 2005). Mt is a dioctahedral smectite with a total (negative) layer charge between 0.2 and 0.6 per half unit cell. Its layer consists of an Al-O octahedral sheet sandwiched between two Si-O tetrahedral sheets. The sheets are covalently connected by common oxygen atoms (Brigatti et al., 2006). Because of the hydrophilic and polycationic nature of chitosan in acidic media, this biopolymer has good miscibility with Mt and can easily intercalate into the interlayer spaces by means of cationic exchange (Wang et al., 2005). It has been proved that chitosan has been intercalated via ionic exchange into negatively charged $\mathrm{Mt}$ interlayer spaces (Margarita et al., 2003). Salcedo et al. (2014) studied the intestinal permeability of oxytetracycline from montmorillonite/chitosan nanocomposite. Giannakas et al. (2014) investigated the characterization, mechanical and water barrier properties of montmorillonite-chitosan nanocomposite and found that a reflux treatment of solution led to a significant improvement of the tested properties of montmorillonite-chitosan nanocomposite films. It had research on the effect of the Mt concentration on the mechanical, barrier properties (Pechyen and Ummartyotin, 2016).

In order to improve the barrier of traditonal package paper against water and vapor, the paper focused on studying the surface properties of package paper by coating montmorillonite/chitosan nanocomposite on the surface of paper. The film forming property and film permeability property were also researched. The effect of Mt dispersion rate, the content of Mt and dispersant in the mixed solution on the surface properties and barrier properties of the coated paper were studied. Scanning electron microscope (SEM), atomic force microscope (AFM), and penetration dynamics analyzer (PDA) were used to analyze the film formation and permeability of montmorillonite/chitosan nanocomposite.

\section{Materials and methods}

\subsection{Materials}

The basis weight of kraft paper was 120 $\mathrm{g} / \mathrm{m}^{2}$ (smoothness: $18.5 \mathrm{~s}$ with Bekk smoothness tester, elongation: $1.51 \%$ with Frank tensile testing machine). Chitosan (Cs) (degree of deacetylation of $80 \%$ to $95 \%$, the molar mass $(\mathrm{Mm})$ is about $\left.1.26 \times 10^{5} \mathrm{~g} / \mathrm{mol}\right)$, supplied by Guoyao Chemical Co., Ltd., China. The acetic acid (99\%), was obtained from Nanjing Chemical Industry Group (China). Montmorillonite (Mt) was bought from Beijing Yue Wei specialized technology companies. Sodium polyacrylate as a dispersant was purchased from Ningbo Jiahua (China). 


\subsection{Preparation of montmorillonite/chitosan nanocomposite \\ montmorillonite/chitosan nanocomposite} $(\mathrm{Mt} / \mathrm{Cs})$ were prepared by the solution intercalation method. $200 \mathrm{~g} 1.5 \mathrm{wt} \%$ chitosan acetic acid solution was prepared, which the dosage ratio of chitosan (dry weight) to glacial acetic acid was 1:0.5. Then added the Mt dispersion (Be dissolved in $1.0 \mathrm{wt} \%$ glacial acetic acid), which the content of Mt (dry weight) with respect to the weight of chitosan (dry weight) respectively was $2 \%$, $5 \%$, and $8 \%$. The dispersion speed of $\mathrm{Mt}$ dispersion was respectively $1200 \mathrm{rpm}, 1500$ $\mathrm{rpm}$, and $1800 \mathrm{rpm}$. The content of dispersant were respectively $0.5 \%$ and $0.9 \%$ of the $\mathrm{Mt}$ (dry weight). The mixed solution was magnetically stirred for 4 hours, then purified by the 200 mesh sieve filter and standing for 30 min to eliminate foam.

\subsection{Coating and Calendering}

The kraft paper were single-side coated by the roll coating machine (PK Print Coat Instruments Ltd., Litlington, Royston, Herts, SG8 0QZ, U.K.). Then the coated paper were dried in the electric heated blast drying oven $\left(105^{\circ} \mathrm{C}\right)$ and calendered by the Calender (pressrure $1 \mathrm{MPa}$ ). After calendered, the coated paper were placed at the constant temperature and humidity environmental to balance water.

\subsection{SEM and AFM}

Scanning electron microscope (SEM) was applied to observe the surface coverage of nanocomposites. The sample paper was imaged with the FEI Quanta 200 environmental scanning electron microscopy (SEM) at $15 \mathrm{kV}$ acceleration voltage. Through the test of atomic force microscope, it can see the change of surface Root Mean Square (RMS) roughness of the coated paper. The sample paper was drawn in a 2-dimensional and a 3-dimensional picture with supporting software NanoScope Analysis 1.40.

\subsection{The paper surface properties analysis}

The smoothness and elongation properties of the coated paper were tested according to GB/450-455/1989.

\subsection{Penetration dynamics analysis (PDA)}

PDA was used to study the properties of the coated paper against water molecular penetrating through it. The PDA curve was applied to represent the penetration and absorption properties of the sample paper (Liu and Chen, 2011). When the curve was steeper, indicated that the liquid penetrated fast.

\subsection{Water vapor permeability (WVP)}

Water vapor permeability (WVP) of the coated paper were measured at the temperature of $35 \pm 2{ }^{\circ} \mathrm{C}$ and a humidity of $70 \pm 2$ RH\% using W3/060 WVP tester. The sample paper were tested once every fifteen minutes, a total of three times. Finally, the last data for the final results.

\section{Results and discussion}

\subsection{Effects of montmorillonite/chitosan nanocomposite Film on the Surface of the Kraft Paper \\ The surface and cross section SEM of the} uncoated and the coated paper with $1.5 \mathrm{wt} \%$ chitosan or $5 \mathrm{wt} \%$ montmorillonite/chitosan nanocomposite (Be dispersed at $1500 \mathrm{rpm}$ without dispersant) were shown in Fig. 1 and 2. Compared to the uncoated paper, there were better and smoother surface for paper coated by chitosan or montmorillonite- 


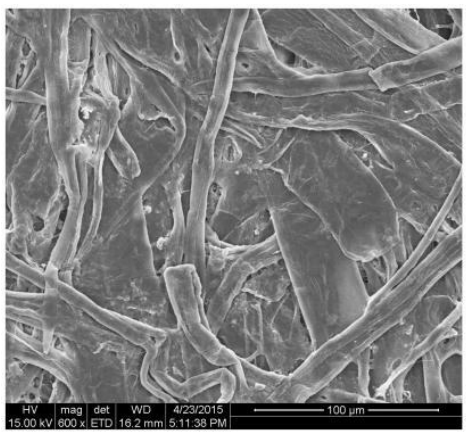

(a)

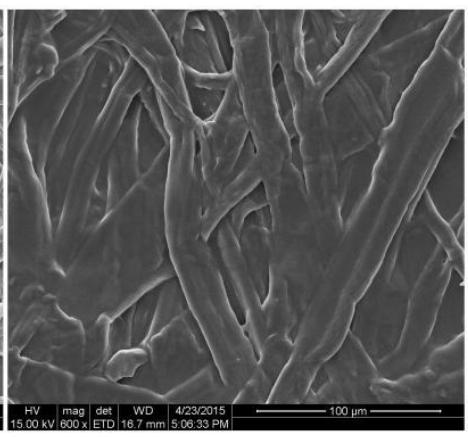

(b)

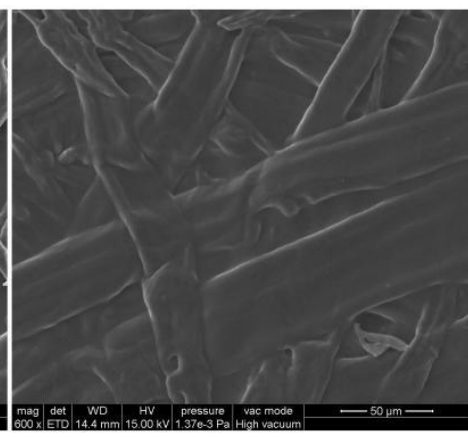

(c)

Fig. 1. The kraft paper surface topography. (a) for the uncoated paper, 600x; (b) for Cs coated paper, $1.59 \mathrm{~g} / \mathrm{m}^{2}, 600 \times$; (c) for Mt/Cs coated paper, $1.59 \mathrm{~g} / \mathrm{m}^{2}, 600 \times$.

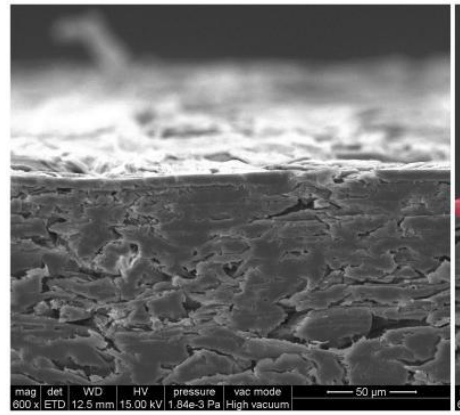

(a)

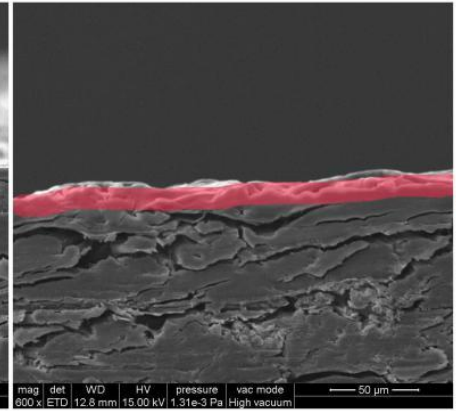

(b)

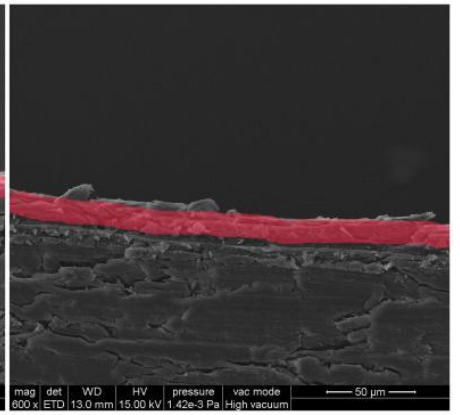

(c)

Fig. 2. The kraft paper cross-section topography. (a) for the uncoated paper, the average thickness of paper is $0.1646 \mathrm{~mm}$, 600x; (b) for Cs coated paper, $1.59 \mathrm{~g} / \mathrm{m}^{2}$, the average thickness of paper is $0.1650 \mathrm{~mm}, 600 \times$; (c) for $\mathrm{Mt} / \mathrm{Cs}$ coated paper, $1.59 \mathrm{~g} / \mathrm{m}^{2}$, the average thickness of paper is $0.1672 \mathrm{~mm}, 600 \times$.

chitosan nanocomposite. It was contributed to the better film formation of chitosan. It was also found that there were a little solution penetrate into the inside of paper coated by montmorillonite/chitosan nanocomposite, compared with the single chitosan coated paper.

Therefore, it could be concluded that montmorillonite/chitosan nanocomposite had a poor film formation on the surface of kraft paper compared with chitosan. The coverage property of chitosan was better than montmorillonite/chitosan nanocomposite.

The AFM topography and three-dimensional map of the uncoated paper and coated paper were shown in Fig. 3. The topography in the left side indirectly shows the case of uncoated paper surface after covered with $1.5 \mathrm{wt} \%$ chitosan or $5 \mathrm{wt} \%$ montmorillonite/chitosan nanocomposite (with the dispersion speed at $1500 \mathrm{rpm}$ and without dispersant adding), three-dimensional map in the right side shows the changes in smoothness of kraft paper after coating. As can be seen from Fig. 3(b) and Fig. 3(c), with the solution coating on the uncoated paper, effectively improved the uneven situation of kraft paper. Moreover, compared with montmorillonite/chitosan nanocomposite solution coated paper, the degree of uneven situation of chitosan coated paper had decreased more obviously. It was because there were differences in the film formation and penetration between chitosan and montmorillonite/chitosan nanocomposite on the surface of kraft paper. It resulted in the different smooth layer on the surface of paper. 

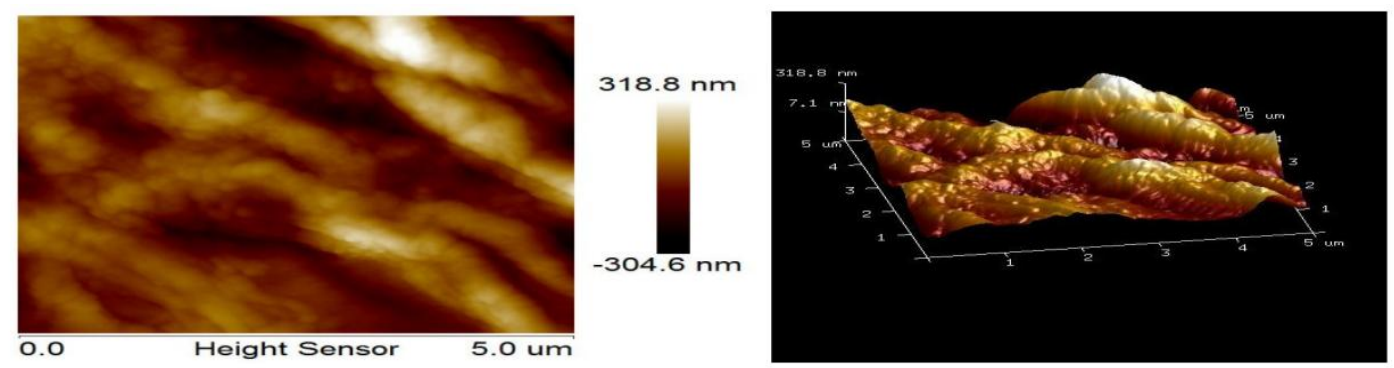

(a) The uncoated paper
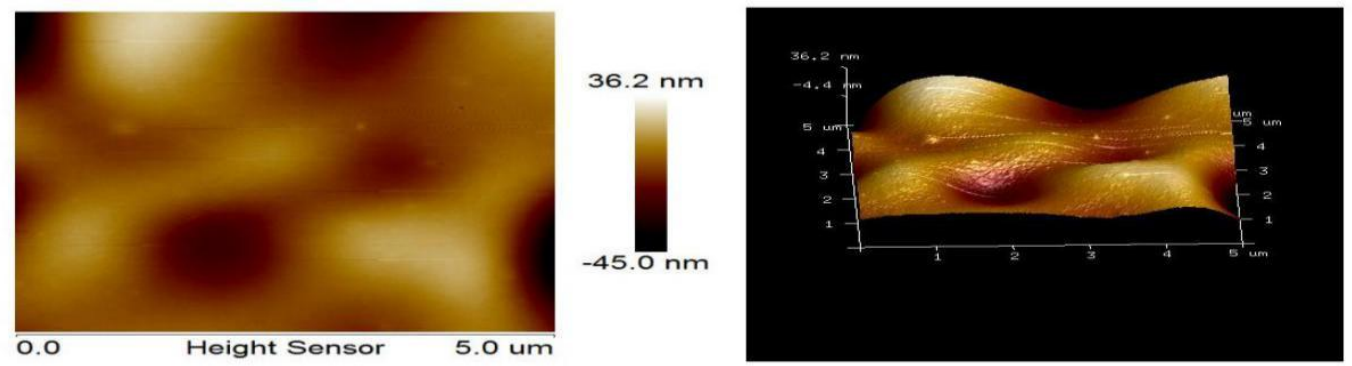

(b) Cs coating weight $2.40 \mathrm{~g} / \mathrm{m}^{2}$
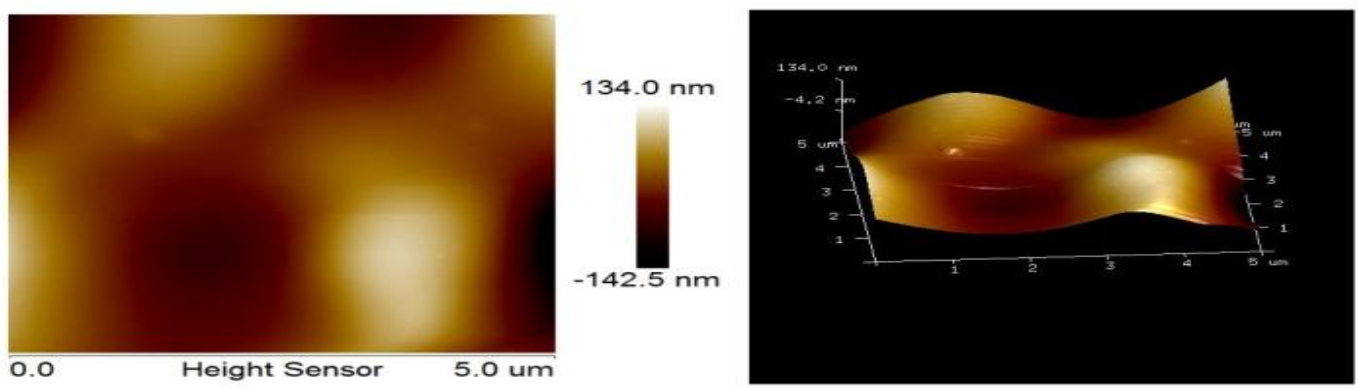

(c) Mt/Cs coating weight $2.40 \mathrm{~g} / \mathrm{m}^{2}$

Fig. 3. AFM views of the uncoated and coated paper.

The Root Mean Square (RMS) roughness of the uncoated paper and coated paper are shown in Table 1. It had further proved that the difference in film uniformity between chitosan and montmorillonite/chitosan nanocomposite. Compared with the uncoated paper, the RMS roughness of paper coated with montmorillonite/chitosan nanocomposite decreased by $53.56 \%$, while chitosan coated paper had decreased by $88.42 \%$.

To sum up, chitosan and montmorillonite/chitosan nanocomposite could form a film on the surface of kraft paper and improve the smooth of paper, but chitosan had a better film formation property than nanocomposite.

\subsection{Effects of Different Process Conditions of $\mathrm{Mt} / \mathrm{Cs}$ on the Properties of Coated Paper}

The smoothness and elongation of montmorillonite/chitosan nanocomposite coated paper are shown in Table 2. Compared to the uncoated paper, the montmorillonite/chitosan nanocomposite coated paper had better smoothness and elongation. However, their smoothness and elongation were lower than pure chitosan coated paper, which owning to the superior formation property of chitosan. 
Table 1

The Root Mean Square (RMS) roughness of different coated paper (with $1.5 \mathrm{wt} \%$ chitosan solution, and the Mt concentration of $5 \mathrm{wt} \%$, dispersion speed at $1500 \mathrm{rpm}$, without dispersant adding).

\begin{tabular}{ccc}
\hline Samples & Coating weight $\left(\mathrm{g} / \mathrm{m}^{2}\right)$ & RMS roughness $(\mu \mathrm{m})$ \\
\hline The uncoated paper & 0 & $0.0872 \pm 0.0003$ \\
Cs-coated paper & 2.40 & $0.0101 \pm 0.0001$ \\
Mt/Cs-coated paper & 2.40 & $0.0405 \pm 0.0003$ \\
\hline
\end{tabular}

The addition of Mt into chitosan solutions resulted in reduction of smoothness and little changes of the elongation. Because Mt dispersion was composed of many particles which had a particle size and shape resulted the uneven surface and poor physical properties of coated paper. Furthermore, the high content of Mt resulted in raising the brittleness of materials (Koh et al., 2008).

The effect of dispersion rate on the dispersed structure of Mt-layers was not to be ignored (Hong et al., 2011). High dispersion speed of $\mathrm{Mt}$ dispersion were helpful to improve the smoothness and elongation of the coated paper, which was caused by a better intercalation effect and composite structure between chitosan and Mt created by high dispersion speed of Mt dispersion.

The data from Table 1 can also discover that the smoothness and elongation of montmorillonite/chitosan nanocomposite coated paper enhanced with the increase of organic dispersant. As a layered silicate, Mt has a good hydrophilic so that it can be present in the solution as a colloidal dispersed state. The effect of the dispersant was to make the system homogeneous, to increase the performance of the dispersion, without precipitation, reduce the solid-liquid interfacial energy and maintain the physicochemical properties of the whole system at the same conditions (Jiang et al., 2010). Some data indicated that the dispersant molecules in the particle surface

Table 2

Results of the Coated Paper Surface and Physical Properties.

\begin{tabular}{|c|c|c|c|}
\hline \multicolumn{2}{|c|}{ Samples } & $\begin{array}{c}\text { Smoothness } \\
\text { (s) }\end{array}$ & $\begin{array}{c}\text { Elongation } \\
(\%)\end{array}$ \\
\hline \multicolumn{2}{|c|}{ The uncoated paper } & 18.5 & 1.51 \\
\hline \multicolumn{2}{|c|}{$1.5 \mathrm{wt} \%$ Cs coated paper } & 29.0 & 1.83 \\
\hline \multirow{4}{*}{$\begin{array}{l}\text { The content of Mt } \\
\text { (Mt/Cs dry weight) }\end{array}$} & $2 \mathrm{wt} \%$ & 28.5 & 1.81 \\
\hline & $5 \mathrm{wt} \%$ & 26.5 & 1.78 \\
\hline & $8 \mathrm{wt} \%$ & 23.0 & 1.73 \\
\hline & $1200 \mathrm{rpm}$ & 24.0 & 1.76 \\
\hline \multirow[t]{3}{*}{ Dispersion speed of Mt } & $1500 \mathrm{rpm}$ & 26.5 & 1.78 \\
\hline & $1800 \mathrm{rpm}$ & 30.0 & 1.85 \\
\hline & $0 \mathrm{wt} \%$ & 26.5 & 1.78 \\
\hline \multirow[t]{2}{*}{ Dosage of dispersant } & $0.5 \mathrm{wt} \%$ & 27.0 & 1.80 \\
\hline & $0.9 \mathrm{wt} \%$ & 28.5 & 1.84 \\
\hline
\end{tabular}


adsorption capacity directly affected the dispersion stability of dispersion system (Singh et al.,2007).

The effects of the coating weight on the smoothness and elongation of the kraft paper are shown in Fig. 4.

The surface smoothness of the coated paper increased up to $66.5 \mathrm{~s}$ when the coating weight was $3.97 \mathrm{~g} / \mathrm{m}^{2}$, which was 2.6 times than $18.5 \mathrm{~s}$ of the uncoated paper itself, as increasing the content of montmorillonite/chitosan nanocomposite. It might be possible result of the thicker film on the kraft paper and uneven surface created by the very high amount of montmorillonite/chitosan nanocomposite. Similarly, when the coating weight was 3.97 $\mathrm{g} / \mathrm{m}^{2}$, the elongation was increased by $31.1 \%$, compared to the uncoated paper itself, as increasing the content of montmorillonite/chitosan nanocomposite. This trend was caused by the resistance and orientation creased by Mt and the aspect ratio of intercalated silicated layer. What's more, the resistance of oriented frame of chitosan chain in interlayer spaces to stretching and the strong surface tension between chitosan and Mt were aslo responsible for increasing elongation (Koh et al., 2008).

\subsection{Effects of Different Process Conditions \\ Of Mt/Cs on PDA Curve of the Coated Paper}

The PDA curve exhibited the significant increase when the kraft paper was coated with nanocomposite materials. The PDA curves including the uncoated paper, chitosan coated paper and various kinds of montmorillonite/chitosan nanocomposite coated paper are showed in Fig. 5.

It was obvious from the obtained results that the intercalation of chitosan matrix into the Mt interlayer spaces leaded to an obvious increase in the effect on resisting against water permeation. These results were a good indication that chitosan molecules and $\mathrm{Mt}$ particle fill the pores of the cellulose fiber network as well as the coating forming a continuous thin film over the surface (Reis et al., 2011). Additionally, with increasing Mt content of the coating, the volume of $\mathrm{Mt}$ particle expanded after absorbing water, the distance for water molecules through the coating layer lengthened, finally resulted that the property of resisting against water permeation of composite coating layers were improved.

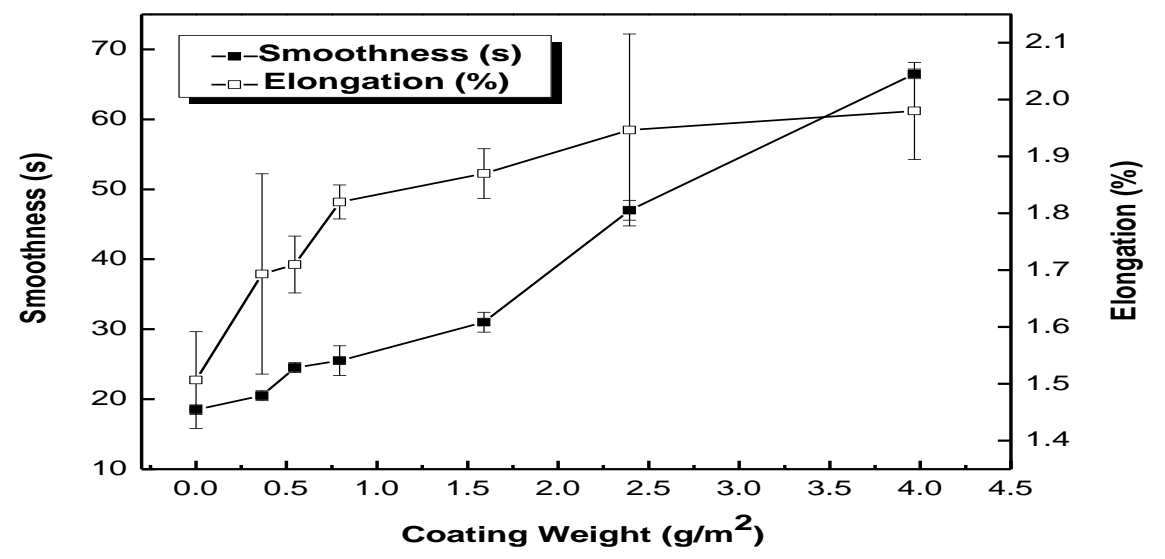

Fig. 4. Effects of Mt/Cs nanocomposites coating weight on the coated paper. 


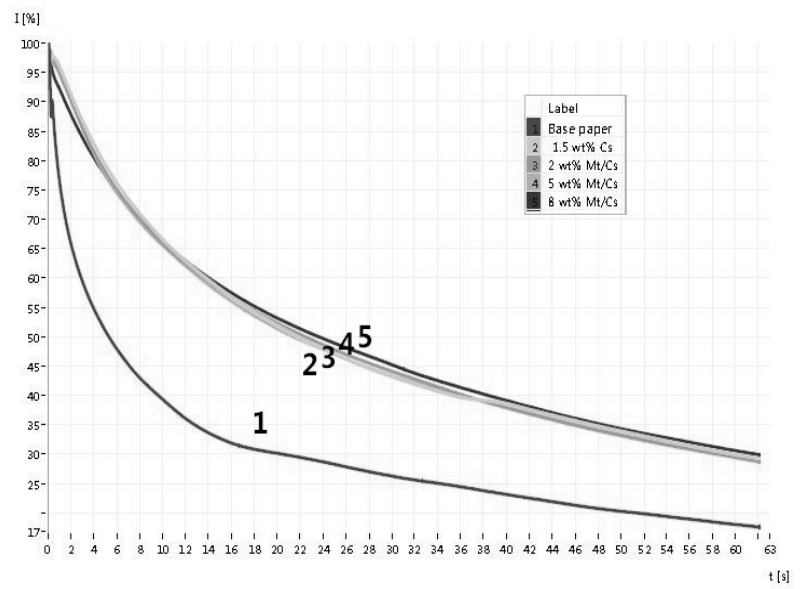

Fig. 5. Different dosage of Mt coated paper PDA curve.

The effect of Mt dispersion speed on resisting water permeation is shown in Fig. 6. The decline rate of crossing signal intensity of montmorillonite/chitosan nanocomposite coated paper had slowed down along with the increase of $\mathrm{Mt}$ dispersion speed. It showed that higher dispersion speed of Mt made Mt more evenly distributed in chitosan which resulted a better performance of montmorillonite/chitosan nanocomposite coated paper on resisting against water permeation.

As can be seen in Fig. 7, the use of dispersant had obviously improved the performance of resisting against water

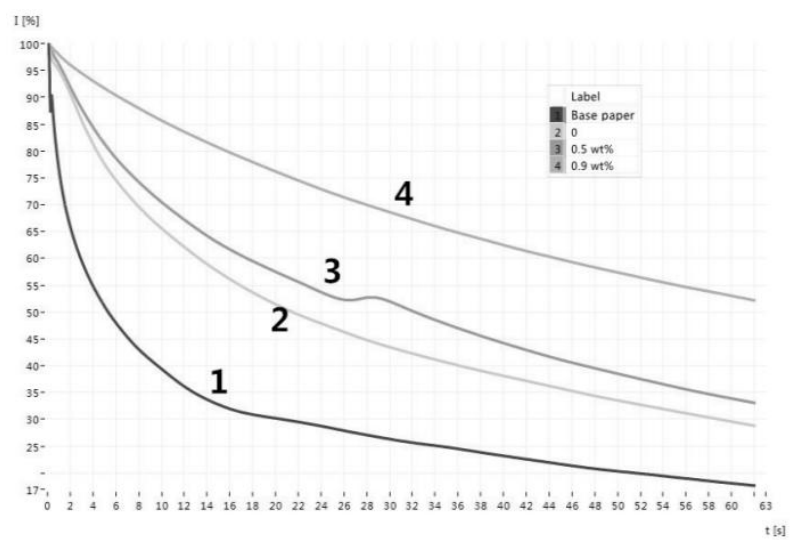

Fig. 7. Different dosage of dispersant coated paper PDA curve.

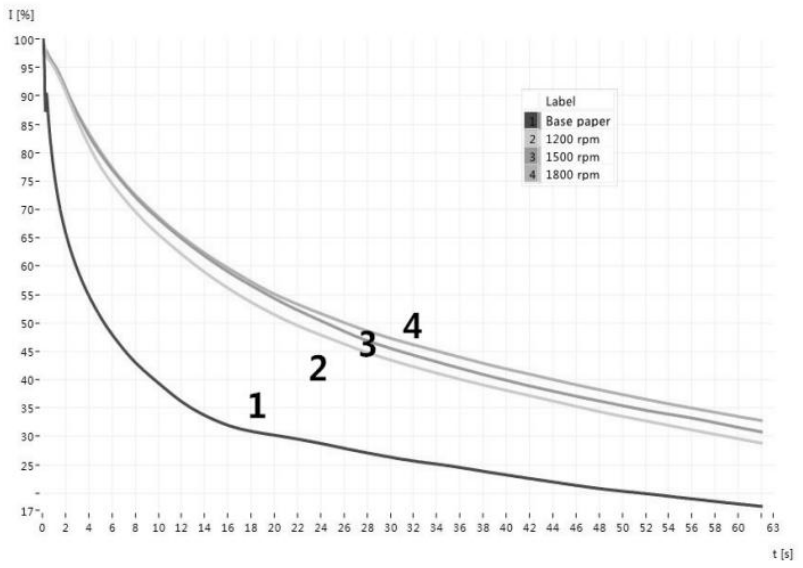

Fig. 6. Different dispersion speed of Mt coated paper PDA curve.

permeation of montmorillonite/chitosan nanocomposite coated paper, which was cause by dispersant increasing the stability of Mt dispersion, making a more uniform dispersion of Mt in chitosan solution.

The effect of the thickness of montmorillonite/chitosan nanocomposite coating layer is shown in Fig. 8. It was apparent that higher coating weight on the kraft paper gained a better effect on resisting to water permeation. This result was considered as the thicker coating layer and enhanced hydrophobicity of montmorillonite/chitosan nanocomposite film on the surface of kraft paper.

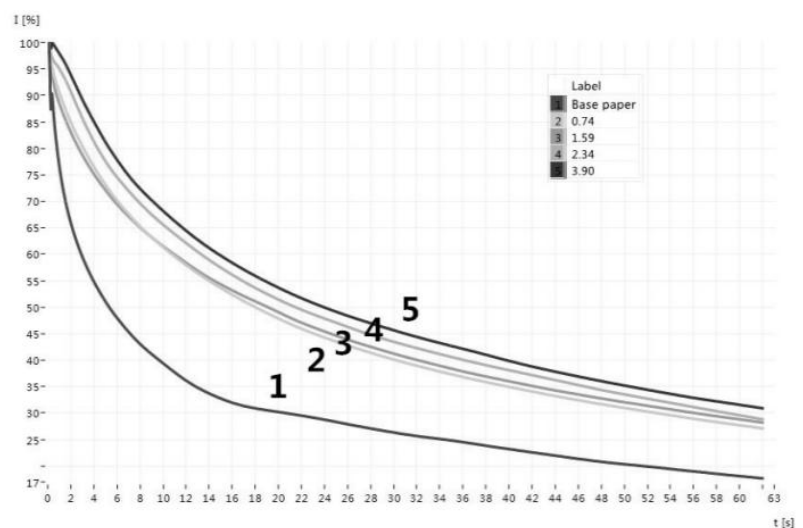

Fig. 8. Different coating weight of the coated paper PDA curve. 


\subsection{Effects of Different Process Conditions on WVP of the Coated Paper}

A significant difference was observed between the WVP values of the chitosan-coated paper and montmorillonite/chitosan nanocomposite coated paper (Fig. 9). It was found that the montmorillonite/chitosan nanocomposite coated paper had a better water vapor barrier property than single chitosan coated paper. Moreover, the WVP of the montmorillonite/chitosan nanocomposite coated paper decreased with the content of Mt increased.

This result was favorable for application in foods with high water absorption. With the addition of a layered silicate filler-Mt, which had a large aspect ratio, the intercalated silicate layer uniformly dispersed in nano-scale into chitosan matrix, so when the gas or liquid small molecule through the same thickness of film, it must bypass these flaky inorganic phase, the tortuosity of the path to be greatly lengthened (Qi and Shang, 2002). In a similar way, the very high content of composite materials on kraft paper made its WVP decreased significantly, which was attributed to the thicker

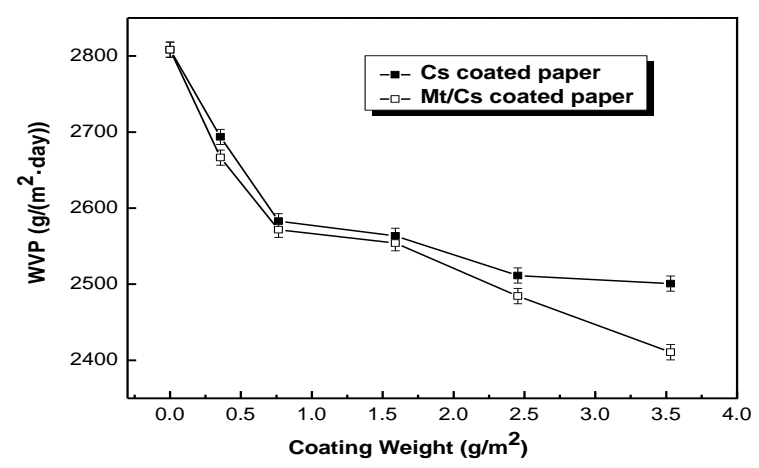

Fig. 9. Effects of coating weight on coated paper WVP. montmorillonite/chitosan nanocomposite coating layer on the surface of kraft paper (Liu and Chen, 2012; Dias et al., 2014).

Water vapor permeability (WVP) of montmorillonite/chitosan nanocomposite coated paper decreased with the increase of Mt content in Fig. 10(A). The downtrend was in according with the WVP of the high coating weight of montmorillonite/chitosan nanocomposite coated paper. It can account for the tortuosity of permeable channel increased with the increase of Mt content.

When compared to WVP of montmorillonite/chitosan nanocomposite coated paper varying with kinds of $\mathrm{Mt}$ dispersion speed in Fig. 10(B), the barrier feature of montmorillonite/chitosan nanocomposite coated paper with $1800 \mathrm{rpm}$ for Mt dispersion was extremely outstanding. It can be the consequence of the lengthened path created by high dispersion rate of $\mathrm{Mt}$ leading to the desirable structure between chitosan and Mt, which Mt were well ordered and dispersed in the chitosan polymer matrix at a dispersion rate of $1800 \mathrm{rpm}$ compared with other Mt dispersion treated with different dispersion rates (Liu and Chen, 2011).

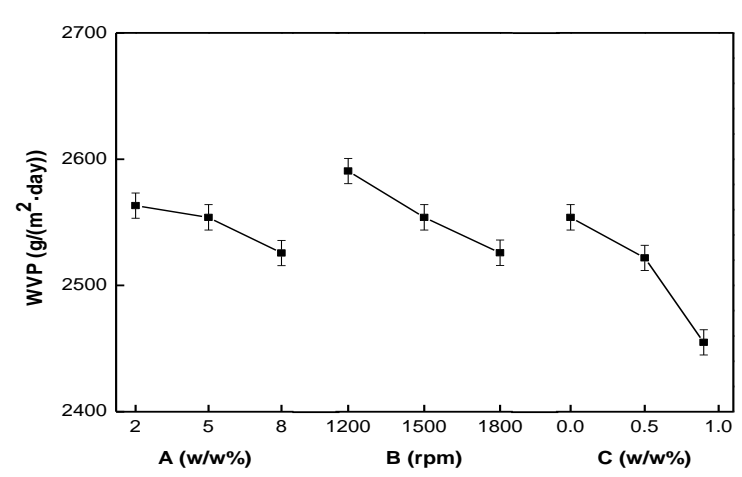

Fig. 10. The results of the coated paper WVP. (A) for the content of $\mathrm{Mt}$; (B) for Mt dispersion speed; (C) for the dosage of dispersant. The WVP of the uncoated paper is $2808.24\left(\mathrm{~g} /\left(\mathrm{m}^{2}\right.\right.$. day $\left.)\right)$. 
From the WVP patterns in Fig. 10(C), the shift decrease with various kinds of $\mathrm{Mt}$ dispersion indicated their dispersibility, therefore it can be considered that more uniformly dispersed and stable Mt dispersion was intercalated into chitosan, forming a desirable structure between chitosan and Mt, which can be described that layered structures between silicate layers were disrupted by intercalated polymers and they were distributed uniformly on polymer matrix. Thus higher content of dispersant in montmorillonite/chitosan nanocomposite coated paper had better water vapor barrier property which was caused by the lengthening equivalent path for gas molecules through the coated paper.

\section{Conclusions}

In summary, chitosan and montmorillonite/chitosan nanocomposite can improve the paper smoothness and reduce the paper roughness. But single chitosan film had better formation than montmorillonite/chitosan nanocomposite. The paper coated with the lower content of Mt, or with the high dispersion speed and the content of dispersant, had better smoothness and elongation. The montmorillonite/chitosan nanocomposite coated paper under the conditions of high coating weight, high dispersion rate for $\mathrm{Mt}$ dispersion, high $\mathrm{Mt}$ and dispersant content in composite materials had better effect on resisting against water permeation, which also had excellent water vapor barrier properties. Based on these results, it is expected to develop montmorillonite/chitosan nanocomposite instead of chitosan to meet the environmental and storage requirement of packaging material in the packaging industry.

\section{Acknowledgements}

This work was financially supported for this work was provided by The National Science Foundation of China (No.31370583), and Brand Specialty Construction First Projects of Jiangsu Universities 2015 (No. PPZY2015C221).

\section{References}

Azhar, F. F., Olad, A., 2014. A study on sustained release formulations for oral delivery of 5-fluorouracil based on alginate-chitosan/montmorillonite nanocomposite systems. Applied Clay Science, 101, 288-296.

Brigatti, M. F., Galan, E., Theng, B. K. G., 2006. STRUCTURES AND MINERALOGY OF CLAY MINERALS. In: Bergaya, F., Theng, B. K. G., Lagaly, G. (Eds.), Handbook of Clay Science. Elsevier, Developments of Clay Science, Volume 1, Amsterdam, pp: 35-44 (Chapter 2)

Dias, M. V., Machado Azevedo, V., Borges, S. V., Soares Nde, F., de Barros Fernandes, R. V., Marques, J. J., et al., 2014. Development of chitosan/montmorillonite nanocomposites with encapsulated alpha-tocopherol. Food Chemistry, 165, 323-329.

Giannakas, A., Grigoriadi, K., Leontiou, A., Barkoula, N. M. Ladavos, A., 2014. Preparation, characterization, mechanical and barrier properties investigation of chitosan-clay nanocomposites. Carbohydrate polymers, 108, 103-111. Han, Y. S., Lee, S. H., Choi, K. H. Park, I., 2010. Preparation and characterization of chitosan-clay nanocomposites with antimicrobial activity. Journal of Physics and Chemistry of Solids, 71, 464-467.

Hsu, S. H., Wang, M. C., Lin, J. J., 2012. 
Biocompatibility and antimicrobial evaluation of montmorillonite/chitosan nanocomposites. Applied Clay Science, $56,53-62$.

He, M., Wang, Z. F., Li, S. D., Yang, X. H., Yang, Z. M. Li, P. W., 2014. Effect of $\mathrm{CTAB}$ on the structure and properties of chitosan/montmorillonoid composite food preservative films. Science and Technology of Food Industry, 35.

Hong, S. I., Lee, J. H., Bae, H. J., Koo, S. Y., Lee, H. S., Choi, J. H., et al., 2011. Effect of shear rate on structural, mechanical, and barrier properties of chitosan/montmorillonite nanocomposite film. Journal of Applied Polymer Science, 119, 2742-2749.

Jiang, X. H., Cao, J. Z., Luo, G., 2010. Effect of different dispersants on the dispersion stability of organic montmorillonite(ommt) suspension. CHINA CERAMICS, 46, 32-35.

Kampeerapappun, P., Aht-ong, D., Pentrakoon, D. Srikulkit, K., 2007.

Preparation of cassava starch/montmorillonite composite film. Carbohydrate polymers, 67, 155-163.

Kittinaovarat, S., Kansomwan, P., Jiratumnukul, N., 2010.

Chitosan/modified montnorillonite beads and adsorption Reactive Red 120. Applied Clay Science, 48, 87-91.

Koh, H. C., Park, J. S., Jeong, M. A., Hwang, H. Y., Hong, Y. T., Ha, S. T., et al., 2008. Preparation and gas permeation properties of biodegradable polymer/layered silicate nanocomposite membranes. Desalination, 233, 201-209.

Lertsutthiwong, P., Noomun, K., Khunthon, S., Limpanart, S., 2012. Influence of chitosan characteristics on the properties of biopolymeric chitosan-montmorillonite. Progress in Natural Science: Materials International, 22, 502-508.
Lewandowska, K., Sionkowska, A., Kaczmarek, B., Furtos, G., 2014. Characterization of chitosan composites with various clays. International journal of biological macromolecules, 65 , 534-541.

Lin, K. F., Hsu, C. Y., Huang, T. S., Chiu, W. Y., Lee, Y. H., Young, T. H., 2005. A novel method to prepare chitosan/montmorillonite nanocomposites. Journal of Applied Polymer Science, 98, 2042-2047.

Liu, Y. S., Chen G., 2012. Study on the paper barrier coating and its barrier properties. Guangzhou: South China University of Technology, 36-37.

Liu, Y. S., Chen G., 2011. Study on the application of chitosan in paper barrier coating. China Pulp \& Paper, 30, 1-6.

Margarita, D., Montserrat, C., Eduardo R. H., 2003. Biopolymer-clay nanocomposites based on chitosan intercalated in montmorillonite. Chem. Mater, 15, 3774-3780.

Pechyen, C., Ummartyotin, S., 2016. Effect of montmorillonite in fish water soluble protein composite film as a prototype of biodegradable packaging materials. Applied Clay Science, 132-133, 430-437.

Qi, Z. N., Shang, W. Y., 2002. Polymer layered silicate nanocomposites theory and practice. Beijing: Chemical Industry Press.

Reis, A. B., Yoshida, C. MP., Reis, A. P. C., Franco, T. T., 2011. Application of chitosan emulsion as a coating on kraft paper. Polymer International, 60, 963-969.

Salcedo, I., Sandri, G., Aguzzi, C., Bonferoni, C., Cerezo, P., Sanchez-Espejo, R., et al., 2014. Intestinal permeability of oxytetracycline from chitosan-montmorillonite nanocomposites. Colloids Surfaces B: Biointerfaces, 117, 441-448. 
Singh, B.P., Jena, J., Besra, L., Bhattacharjee,

S., 2007. Dispersion of nano-silicon carbide(sic) power in aqueous suspensions. Journal of nanoparticle research, 9, 797-806.

Wang, S. F., Shen, L., Tong, Y. J., Chen, L., Phang, I. Y., Lim, P. Q., et al., 2005. Biopolymer chitosan/montmorillonite nanocomposites: Preparation and characterization. Polymer Degradation and Stability, 90, 123-131.

Xu, Y. L., Xiao, H., Qian, X. Z., 2005. Structure and properties of chitosan/montmorillonite hybrid nanocomposite. Journal of Functional Polymers, 18, 383-385. 